\title{
How can philosophy of language help us navigate the political news cycle?
}

\author{
Teresa Marques \\ University of Barcelona \\ teresmatosferreira@ub.edu
}

In this chapter, I try to answer the above question, and another question that it presupposes: How can philosophy of language help us navigate the news cycle? The presupposed question is: can philosophy of language help us navigate the political news cycle? A reader can be sceptical of a positive answer to the latter question; after all, citizens, political theorists, and journalists seem to be capable of following current politics and its coverage in the news, and there is no reason to think that philosophy of language in particular should be capable of helping people make sense and respond to the news.

I should first clarify what I take philosophy and philosophy of language to be concerned with. I don't mean to give a definition of philosophy, but merely an idiosyncratic and rough view of what I take myself to be engaged in. I take philosophy to be a critical, reflective, honest, and systematic investigation, carried out in dialogue with other people (dead or alive!), into the more fundamental and general topics that we, as humans, can care about in our relationship and experiences with the world and each other. It includes the reflection about whether we can know anything, how we can meaningfully communicate with each other, whether anything is right or wrong, good or bad, what is the meaning of life, if there's any meaning in life, or how we should organize ourselves socially and politically.

Philosophy of language, as you can guess, investigates how we can meaningfully communicate with each other. But philosophy of language is not philology: it does not study 
particular languages such as Portuguese or Spanish. It is also not linguistics, although it is often informed by, and informs, research in linguistics. Philosophy of language investigates general concepts that are central to our use of language - meaning, reference, truth - and in relation to our linguistic capacity and practice as humans.

It might be surprising, then, to ask such a concrete applied question as the title of this chapter does. In recent years, however, more and more philosophers of language are trying to understand what politicians say and mean, what their statements reveal about their plans, what they expect from voters, or which linguistic mechanisms are deployed in political propaganda. In the last decades, several philosophers of language have started to deploy their skills and theoretical tools (let's call them that) to explain the differences between lying, misleading, and deceiving, and whether these have the same negative moral value. Or how politicians can convey racist or xenophobic messages, while plausibly denying doing so. Or, still, the semantic and pragmatic mechanisms operating in what George Orwell called doublethink and doublespeak.

I'm just one among many female philosophers engaging in applied philosophy of language: Saray Ayala, Claudia Bianchi, Renée Bolinger, Elisabeth Camp, Laura Caponetto, Bianca Cepollaro, Esa Díaz-León, Robin Jeshion, Rae Langton, Mary Kate McGowan, Ishani Maitra, Eleonore Neufeld, Jennifer Saul, Marina Sbisá, Laura Schroeter, Rachel Sterken, or Lynne Tirell are just a few of the many women doing this kind of work. Now, I don't have an explanation as to why there are so many female philosophers especially interested in applied philosophy. There's a Wikipedia page on women in philosophy that portrays the low numbers of professional women in philosophy in the USA and the UK. Perhaps there's a connection between being underrepresented in one's profession and trying to make sense of concrete problems in the world, but this is a mere hypothesis that I am in no position to test. And it might be wrong!

In the remaining of this chapter, I will illustrate the application of philosophy of language to 
three contrasting strategies of political propaganda: dogwhistles, meaning perversions, and baldfaced lies. I hope that these help us see that philosophy of language can be a good tool in diagnosing demagoguery, and in resisting it.

\section{Dogwhistles}

In 2011, before Obama's re-election in 2012, Donald Trump tried to alarm people about that prospect:

If we keep on this path, if we re-elect Barack Obama, the America we leave our kids and grandkids won't look like the America we were blessed to grow up in. The American Dream will be in hock. The shining city on the hill will start to look like an inner-city wreck. (Trump, 2011, Time to Get Tough: Making America \#1 Again).

Very notably, Trump uses words that have a real-world reference. He used "shining city on the hill" to refer to the United States, and used "inner-city wreck" to talk about city centres. Trump was not merely referring to the US or central urban areas. He was also conveying a contrasting positive and negative value by using those expressions. This additional conveyed message is not explicit in the sentences used. For simplicity, we can paraphrase what he explicitly said as "If we re-elect Obama, America will start to look like an inner-city wreck”. But what he implicitly conveys is rather "If we re-elect Obama, America will start to be dominated by poor, lazy, criminal black people.” In the US, as is discussed by Jennifer Saul, it is known that 'inner city' works as a way to negatively refer to black people (Tali Mendelberg, in her book, The Race Card, talks of such implicit political communication and how it can change the acceptability of racist discrimination in the US, mostly after the 1960s). Now, a racist dogwhistle, as a form of implicitly political communication, allows a speaker to violate a norm of racial equality with plausible deniability. In fact, a speaker like Trump can try to get away from accusations of racism with: "I didn't say anything about race, you're the one playing the race card!" 
How can philosophy of language help us in understanding how dogwhistles convey such racist contents? Jennifer Saul distinguishes between overt and covert dogwhistles. Her distinction can be summarized as follows:

Overt dogwhistles are designed with intent to allow two plausible interpretations:

(i) a private content aimed at a desired target audience - for instance, George W. Bush's use of 'wonder-working power' during an election as a dogwhistle to reach Christian evangelical fundamentalists, who would take it as a sign of faith in the power of Christ.

(i) a plausible non-racist content for a broader audience.

- Covert dogwhistles, for instance 'inner city' as used by Donald Trump above, are designed with intent to get an audience that disapproves, e.g., of explicitly racist speech, but who feels ok with apparently reasonable claims that are implicitly discriminatory.

Now, there is quite a lot of debate about how exactly dogwhistles convey their implicit racist content and animate racial resentment. I can't get into the details of this debate here. But a central feature especially of covert dogwhistles is that they allow for the negation, without contradiction, of the presumed racist content conveyed. In that regard, they contrast with other phrases that communicate something that is not explicitly stated or asserted. Consider for instance, the following: "It was Betty who bought the last copy of Invisible Women. No one bought the last copy of Invisible Women". The first sentence seems to presuppose, but does not state, what is denied by the second sentence. Because of that, the two together appear contradictory. If there is any contradiction, it must be because the meaning of "it was Betty who did so-and-so" presupposes that so-and-so did happen. Now, in contrast, even if unlikely, Trump could have said, "If we reelect Obama, America will start to look like an inner-city wreck. But I don't have anything against poor black people; my best friends are black and I donate to charities to help inner-cities." There is no contradiction in saying both sentences in the same breath, although we could suspect that what came after "But I don't..." is not sincere. 
A second feature of dogwhistles is that the racist implicit content they convey can be reinforced and be mode more explicit. Yet, not all communicated content that is not explicitly asserted allows for this. Here's what I mean. Suppose someone says "It was Betty who bought the last copy of Invisible Women; and what's more, someone bought the last copy of Invisible Women!" The normal response to hearing these two sentences is to say "yeah, I know, you just said it was Betty who did it".

The lesson here is that content that is not asserted, but seems rather to be presupposed, is automatically accommodated by the audience (unless someone interrupts the speaker, saying for instance, "hey, wait a minute! I didn't realize that...”). In the example I gave earlier, it is the proposition that someone bought the last copy of Invisible Women that is automatically accommodated. Unless someone objects with surprise, that proposition will now be taken for granted by the interlocutors. Moreover, it will sound redundant if it is explicitly asserted. In short, reinforcement sounds like redundancy. However, it would not be redundant for Trump to reinforce the implicitly racist message of his statement by adding something explicitly racist, for instance saying: "If we re-elect Obama, America will start to look like an inner-city wreck. And what's more, I think that the guy is lazy. It's probably not his fault, because laziness is a trait in blacks."

These two features of dogwhistles, that what they implicitly convey can be plausibly denied without contradiction, and that what they implicitly convey can be reinforced without redundancy, indicate that the implicit message is conveyed pragmatically. It would seem, then, that dogwhistles work as conversational implicatures, a notion introduced by Paul Grice. With an implicature, a speaker can imply one thing by saying something else. With conversational implicatures, speakers take advantage of cooperative conversational principles or maxims, such as the conversational maxims: Be truthful! Be relevant! As an illustration of the maxim of relevance, if my best friend asks me if I'll go to the concert next week, and I reply, 'I've got to finish to grade my student's 
papers" she will take me to mean that I cannot go to the concert, although I did not say so out loud. She can infer that is what I meant because she assumes that I what say is a relevant answer

I think that dogwhistles depend on something like conversational implicatures, although this is not the place to make that argument. Intuitively, the motivating idea can be easily grasped: What is the relevance of bringing up city centres, which (the audience presumably assumes) are overpopulated, crime-ridden, and whose population is mostly, while advising against re-electing the first black president? Unless there is some connection between the two, the audience would not take the speaker to be saying something relevant.

As I said earlier, I won't have the space here to explain how I think that pragmatic process operates. But I want to point to an effect of the use of racist dogwhistles. It seems that the implicit political content they communicate nonetheless succeeds in changing what speakers take for granted, in particular, in changing the social norms that regulate permissible behaviour. This is, perhaps, the most serious consequence of the use of dogwhistles in political propaganda. The lesson here is that we should make sure whether we are accepting something that sounds reasonable, and perhaps even true, but at the same time acquiescing to racist or xenophobic attitudes. Knowing how dogwhistles actually work (semantically or pragmatically) is hence important to properly asses their impact, and respond to coded discourse.

\section{Meaning perversions}

In an excellent article from 2017 in the New York Review of Books, "The Autocrat's Language", the journalist and writer Masha Gessen wrote:

A Russian poet named Sergei Gandlevsky once said that in the late Soviet period he became obsessed with hardware-store nomenclature. He loved the word secateurs, for example...In a world where words were constantly used to mean their opposite, being able to call secateurs 
"secateurs"- and nothing else-was freedom. "Freedom," on the other hand, was, as you know, slavery. That's Orwell's 1984. And it is also the USSR, a country that had "laws," a "constitution," and even "elections," also known as the "free expression of citizen will..." There was nothing free about it, it did not constitute expression, it had no relationship to citizenship or will because it granted the subject no agency... it eviscerated the words "election," "free," "expression," "citizen," and "will," and it also left the thing itself undescribed... an experience that could be accurately described as, say, an "election," or "free," had been preemptively discredited because those words had been used to denote something entirely different.

The examples that Gessen gives of words whose meaning is perverted in the mouth of the autocrat recall what George Orwell called doublespeak and doublethink. It is no accident that she mentions Orwell's 1984 and one of the doublethink pairs from the book: "freedom is slavery". So, what do propaganda slogans like "The free expression of citizens will!" do? They seem to exploit the normative or evaluative connotation of literal sincere uses of a phrase. For instance "Free homeland!" seems to have a positive connotation as good and desirable, whereas "the enemy of the people" is just the opposite. That positive value of "free" is exploited to induce acceptance of the regime and its practices. To refer to the ritual in the former USSR as a "free election" would make it hard to resist the regime's control - A citizen would be faced with questions like "how can you be against the free exercise of citizens will?"

My view is that meaning perversions are undermining norm-enforcements. While they appear to rely on, and enforce, shared norms or values (of justice, politics, or morality), they actually undermine and erode those very same norms. In other words, they are like a wolf in sheep's skin. Meaning perversions differ from dogwhistles in significant aspects. While meaning perversions exploit pre-existing normative connotations that are common knowledge, and use word to denote an unsuitable referent, for instance, 'freedom' to talk about slavery, or 'free expression of citizen will' for a compulsory ritual that is not an exercise of citizens' agency. Dogwhistles in contrast are words that are used to denote their proper referents, while used to convey that those 
referents have a positive or negative value that in fact they lack. Now, with a dogwhistle, a speaker can deflect criticism of the implicitly conveyed content with plausible deniability - "I didn't say anything about race, you're the one playing the race card again!" In contrast, with a meaning perversion, the speaker can deflect criticism by appearing to enforce, while undermining, the norms or values the word actually connotes: "How can you: be against free elections? Against democracy? The will of the people? Taking back control? Defend an enemy of the people?"

We should pay attention and check if the norms and values that are being conveyed in political discourse actually fit the things the speaker is talking about - free elections are a good and desirable thing, but what if the speaker is referring to a process that is coerced and is not the exercise of political deliberation by all citizens in equal conditions? Contemporary examples abound. For instance, the slogan "take back control" used by the Leave campaign during the 2016 Brexit referendum presupposes that British people lost control (of what, exactly?) at some point, so it would be a good thing for Britons to exercise their autonomy and regain control over their political future. But what if Britain never lost control - not in any relevant sense, at least - and leaving the European Union is in fact a way to lose not just political but also financial control of the future of the UK?

The lesson here is that we should pay attention and check if by accepting something apparently desirable we are actually buying into something against our best interests. The media has an option in deciding whether to repeat political discourse as it is produced - including dogwhistles and the doublespeak, or to paraphrase it with the correct connotations of norms and values, and denoting the right referents. Deliberation in liberal democratic societies requires that journalists and regular citizens are aware that they should make their decisions on the basis of a reflective and critical assessment of political demagoguery. This brings us to the last case study I will discuss. 


\section{Bald-faced lies}

Everybody lies, and naturally all politicians lie. But not everyone lies brazenly, all the time, with confidence, and without trying to conceal that what they say is false. Those who do so with such blatant shamelessness - bald-faced liars - can pose a particular kind of threat to others when they enter the public political domain. In 2017, the New York Times published what it regrettably called "The Definitive List of Donald Trump's Lies", which was definitely not definitive (at the end of 2019 the Washington Post reported that Trump had lied as a president over 15000 times). Here's an excerpt, from only half of October 2017, from the New York Times article. Trump's claims are followed with fact-checking (there were links to relevant news articles in the original):

Oct. 16 "I hear that Ireland is going to be reducing their corporate rates down to 8 percent from 12." (Ireland has no plans to cut its tax rate.) Oct. 16 "If you look at President Obama and other presidents, most of them didn't make calls." (They did call families of soldiers killed in action.) Oct. 16 "All I can say is it's totally fake news, just fake. It's fake. It's made-up stuff, and it's disgraceful what happens, but that happens in the world of politics." (Trump himself has bragged about groping women.).. Oct. 17 "Right now, we are the highest-taxed nation anywhere in the world. You can even say developed or undeveloped." (We're not.) Oct. 17 "As far as I'm concerned, I think we're really essentially the highest. But if you'd like to add the developed nation, you can say that, too." (Taxes in the U.S. are lower than in most developed countries.)... Oct. 17 "I wish President Obama didn't get out the way he got out. Because that left a vacuum and ISIS was formed." (The group's origins date to 2004.) Oct. 18 "Democrat Congresswoman totally fabricated what I said to the wife of a soldier who died in action (and I have proof)." (The wife confirmed Representative Frederica Wilson's account.) Oct. 18 "The Coast Guard in Texas saved 16,000 lives." (The real number was smaller.) Oct. 18 "Nobody has ever heard of a five hitting land." (Category 5 storms have hit land before.) Oct. 24 "Under our plan, more than 30 million Americans who own small businesses will get a 40 per cent cut to their top marginal tax rate." (The real number is estimated to be less than 1 million.) Oct. 25 "We have trade deficits with almost everybody." (We have trade surpluses with more than 100 countries.) Oct. 27 "Wacky \& totally unhinged Tom Steyer, who has been fighting me and my Make America Great Again agenda from beginning, never wins elections!" (Steyer has financially supported many winning candidates.)

It is either common ground that each of those claims are lies, or it can be easily learned since the correct information is publicly available. But what is the effect of such a deluge of lies on 
public discourse? In January 2019, Dahlia Lithwick correctly diagnosed the problem in an article in Slate: "We've grown so hopelessly accustomed to a journalism reduced to daily fact checking, and a politics reduced to daily fact checking, and fact checking reduced to daily white noise that we forget that there is more to daily public life than endlessly correcting the record." The effects of such 'daily white noise' on democratic deliberation are very serious. This deluge of blatant shameless lies is a means of dominating the conversation, manipulating the public, and ultimately controlling reality. Here, philosophy of language can once more help us to understand the mechanism at work.

An effect of having our beliefs and knowledge contradicted with such confidence - what the philosopher J.L. Austin called a perlocutionary effect - is that we often start to doubt what we previously took for granted. This is a psychological effect, studied as gaslighting. We can deploy good semantic and pragmatic theories to explain what the bald-faced liar is doing, and not just the effects of his actions. The bald-faced liar blatantly violates what Paul Grice called The Cooperative Principle of conversations of which the conversational maxims I referred to earlier are a part $(B e$ truthful! Be relevant! etc).

The Cooperative Principle says: Make your contribution such as is required, at the stage at which it occurs, by the accepted purpose or direction of the talk exchange in which you are engaged. The principle assumes that cooperative participants in a conversation try consider the purposes and interests of the conversational setting, as well as other things that they take for granted; and in so doing they should be truthful, perspicuous, relevant, not redundant, etc. But a bald-faced liar blatantly ignores or violates the accepted shared purposes of conversations. He confidently, and shamelessly, says what is commonly known, that is, taken for granted, to be false, and in so doing indicates that he is not interested in being cooperative. Rather, he forces others to accept his purposes and to control the direction of the conversation. In politics, in particular, this 
strategy can have tremendous effects: the replacement of the joint deliberative process of open debate that is central to liberal democracies with the assertion of power and domination of autocracy. As Masha Gessen wrote in another 2016 article in the New York Review of Books, "The Putin Paradigm":

Lying is the message. It's not just that both Putin and Trump lie, it is that they lie in the same way and for the same purpose: blatantly, to assert power over truth itself. Take, for example, Putin's statements on Ukraine. In March 2014 he claimed that there were no Russian troops in newly annexed Crimea; a month later he affirmed that Russians troops had been on the ground. Throughout 2014 and 2015, he repeatedly denied that Russian troops were fighting in eastern Ukraine; in 2016 he easily acknowledged that they were there. In each case, Putin insisted on lying in the face of clear and convincing evidence to the contrary, and in each case his subsequent shift to truthful statements were not admissions given under duress: they were proud, even boastful affirmatives made at his convenience... Putin's power lies in being able to say what he wants, when he wants, regardless of the facts.

We can, and should, understand what the point of such brazen lying is, and should think of our role in public debate, either as journalists or as individual citizens. Political opposition and differences of opinion are not only legitimate in democracies, but are one of the fundamental bases of democracy itself. Deliberative democracy is based on the idea that all people are fundamentally equal in rights and obligations under the law, and that other parties - whatever their status or views - are equally legitimate participants in public life. Strong disagreement and opposition are legitimate in democracy. But they require a common ground of truth and facts, of trust in rational ways to find out what our reality is before we decide what to do, of respect for the legitimacy of differences of opinion, and respect for the rule of law and for the institutions that protect democratic participation and representation.

Understanding mechanisms of political demagoguery such as dogwhistles, meaning perversions, or bald-faced lies, is necessary to understand and respond appropriately to the threats 
they pose to rational deliberation in democratic societies. This brief chapter serves as an illustration of how philosophy of language can help us navigate the political news cycle, and, I hope, confirms that philosophy of language can indeed help us make sense of political debate. 